\title{
GRAIN BOUNDARY PRECIPITATION STRENGTHENING OF PHOSPHORUS-ADDED NICKEL-IRON BASE SUPERALLOY
}

\author{
Yusaku Hasebe $^{1}$, Koichi Takasawa ${ }^{1}$, Takuya Ohkawa ${ }^{1}$, Eiji Maeda ${ }^{1}$, Takashi Hatano ${ }^{1}$ \\ ${ }^{1}$ The Japan Steel Works, Ltd., Muroran Research Laboratory; 4 Chatsu-machi, Muroran, Hokkaido, 051-8505, Japan
}

Keywords: nickel-iron base superalloy, phosphorus, time to rupture, minimum creep rate, grain-boundary precipitate, grain-boundary coverage, grain-boundary precipitation strengthening

\begin{abstract}
Creep properties of a model nickel-iron base superalloy with phosphorus (P) content of 8 to $450 \mathrm{ppm}$ by mass have been investigated at $973 \mathrm{~K}$ under a stress of $333 \mathrm{MPa}$. The P-doped alloys exhibit many grain-boundary precipitates in which niobium and phosphorus are enriched after a certain heat treatment condition prior to the creep test. An alloy with $\mathrm{P}$ of $130 \mathrm{ppm}$ shows a maximum value of grain-boundary coverage by the precipitates (designated as $\rho$ ) of 0.56 . The time to rupture and minimum creep rate correspond well to the value of $\rho$. The rupture life was extended by up to 30 times and the minimum creep rate was decreased by more than two orders of magnitude in the alloy with $\mathrm{P}$ of $130 \mathrm{ppm}$, with respect to those in an alloy with $\mathrm{P}$ of 8 ppm where $\rho=0$. The grain-boundary precipitates remarkably delay the onset of accelerating stage (tertiary creep stage), thereby leading to the longer rupture life. These results strongly suggest that optimization of the $\rho$ value is a key to improve the creep properties of the alloys.
\end{abstract}

\section{Introduction}

Highly sophisticated heat resistant alloys are crucially necessary for putting the future thermal power generation into practical use. For example, a turbine rotor used for advanced-ultra super critical (A-USC) power generation, which is one of the most promising and efficient technologies, will be exposed to high temperature steam at temperature above $700{ }^{\circ} \mathrm{C}$, and is required to meet a stringent technical target; greater than $100 \mathrm{MPa}$ for the $10^{5}$ hours creep strength [1]. Therefore, nickel or nickel-iron base superalloys are being developed as possible candidates for the large components of A-USC plants rather than conventional ferritic heat resistant steels [2-4].

If alloying elements can be used without any restriction, there will be many ways to strengthen these superalloys, for example, solid solution hardening and precipitation hardening with the gamma prime phase [5]. However, the chemical compositions of the nickel-iron base superalloys for large components are often optimized, in particular if used for large components, to avoid macrosegregation during ingot-making [6]. Some previous studies reported that phosphorus, which is classified as harmful element
$[7,8]$ and is usually eliminated as low as possible in the melting process to avoid ductility loss, has beneficial effects in improving the creep properties of nickel-iron base superalloy Inconel $718^{\mathrm{TM}}$. Liu et al. [9] reported that the addition of phosphorus up to 130 ppm increased the creep rupture life of Inconel $718^{\mathrm{TM}}$ at $650{ }^{\circ} \mathrm{C}$, $686 \mathrm{MPa}$. They mentioned that the interaction among phosphorus, grain boundaries and metallic elements might be responsible for the desirable increase in creep resistance. Sun et al. [10] showed that the addition of phosphorus up to $160 \mathrm{ppm}$ decreased the creep rate and increased the creep rupture life at $650{ }^{\circ} \mathrm{C}$. They assumed that the decrease of creep rate was due to the solid solution strengthening of phosphorus addition. Heaney et al. [11] also confirmed the beneficial effects of phosphorus on the creep properties of Inconel $718^{\mathrm{TM}}$ at approximately $593{ }^{\circ} \mathrm{C}\left(1100^{\circ} \mathrm{F}\right)$, and reported that the optimum phosphorus content is in a range of 80 to $150 \mathrm{ppm}$. There are several other reports on the influence of phosphorus on the creep properties of Inconel $718^{\mathrm{TM}}$, and in most cases phosphorus has a positive effect in increasing the creep rupture life [12-15].

However, the details on why phosphorus improves the creep strength has not been adequately revealed in the above mentioned studies. In general, because grain boundaries of heat resistant alloys become weak as temperature increases [16], appropriate methods should be employed to strengthen the grain boundaries at elevated temperatures [17]. Takeyama [18] has advocated the principle of grain-boundary precipitation strengthening with intermetallic compound such as Laves phase, and developed a new class of austenitic heat resistant steels with superior creep rupture life. Grain boundary coverage, which represents the percentage of the grain boundary covered with precipitates, is the important measure for evaluating the effect of grain-boundary precipitation strengthening [19]. Presumably, phosphorus exhibits some sort of grain boundary strengthening effects. However, no attempt has been made on the relationship between creep properties and grain boundary coverage in case of phosphorus doped alloys. The aim of this work thus was set to investigate the effect of phosphorus on the creep properties of a nickel-iron base superalloy, especially from a viewpoint of grain-boundary precipitation strengthening.

Table I . Chemical compositions of the model alloys studied (mass\%).

\begin{tabular}{c|cccccccccc|ccc}
\hline Alloy & $\mathrm{C}$ & $\mathrm{Si}$ & $\mathrm{Mn}$ & $\mathrm{P}$ & $\mathrm{Ni}$ & $\mathrm{Cr}$ & $\mathrm{Al}$ & $\mathrm{Ti}$ & $\mathrm{Nb}$ & $\mathrm{Fe}$ & $\mathrm{N}$ & $\mathrm{O}$ & $\mathrm{S}$ \\
\hline S1 & 0.011 & 0.01 & 0.01 & 8 & bal. & 15.40 & 1.24 & 1.41 & 2.08 & 38.24 & 7 & 16 & 3 \\
S2 & 0.011 & 0.01 & 0.01 & 45 & bal. & 15.41 & 1.26 & 1.45 & 2.05 & 38.26 & 13 & 16 & 2 \\
S3 & 0.012 & 0.01 & 0.01 & 130 & bal. & 15.40 & 1.26 & 1.44 & 2.06 & 38.30 & 12 & 15 & 2 \\
S4 & 0.010 & 0.01 & 0.01 & 200 & bal. & 15.52 & 1.25 & 1.45 & 2.08 & 38.20 & 9 & 16 & 3 \\
S5 & 0.012 & 0.01 & 0.01 & 450 & bal. & 15.52 & 1.25 & 1.46 & 2.09 & 38.18 & 9 & 19 & 3 \\
\hline
\end{tabular}

$\mathrm{P}, \mathrm{S}, \mathrm{N}, \mathrm{O}: \mathrm{ppm}$ by mass 


\section{Experimental procedure}

\section{$\underline{\text { Samples preparation }}$}

The alloys used in this study have a chemical composition of Ni$38 \mathrm{Fe}-15 \mathrm{Cr}-1.3 \mathrm{Al}-1.4 \mathrm{Ti}-2.1 \mathrm{Nb}$ by mass $\%$ with different amount of phosphorus in a range of 8 to $450 \mathrm{ppm}$ by mass, designated as $\mathrm{S} 1$ $\sim \mathrm{S} 5$, as shown in Table I. These alloys were prepared using a vacuum induction melting of $50 \mathrm{~kg}$ ingots. (Hereinafter, mass ppm is abbreviated by ppm.) The phosphorus contents of S1 to S3 were determined by glow discharge mass spectrometry, and those of the other alloys were determined by inductively coupled plasma atomic emission spectrometry. The ingots were annealed at $1200{ }^{\circ} \mathrm{C}$ for $50 \mathrm{~h}$ to eliminate microsegregation, and then were hot-forged into plates of approximately $1230 \mathrm{~mm}$ in length, 100 $\mathrm{mm}$ in width and $35 \mathrm{~mm}$ in thickness. After forging, a solution heat treatment was done at $1040{ }^{\circ} \mathrm{C}$ for $5 \mathrm{~h}$ for $\mathrm{S} 1$ to $\mathrm{S} 4$, and at $1090{ }^{\circ} \mathrm{C}$ for $5 \mathrm{~h}$ for $\mathrm{S} 5$, to attain a uniform grain size. After the solution heat treatment, the plates were cooled in air, and then, the plates were aged in a double-stage process. The purpose of the double-stage of aging were two-fold: to completely dissolve the gamma prime phase precipitated during cooling process after solution heat treatment at the first stage, and to adequately precipitate it at the second stage. The first aging stage was at $840{ }^{\circ} \mathrm{C}$, which is just above the solvus temperature of gamma prime phase, for $10 \mathrm{~h}$, and the second one was $730{ }^{\circ} \mathrm{C}$, which is lower than the solvus temperature of gamma prime phase, for $24 \mathrm{~h}$. The conditions of heat treatment are shown in Figure 1.

Specimens for tensile and creep test were taken from the plates perpendicularly to the forging direction. The dimensions of the specimens were determined in accordance with Japan Industrial Standard (JIS) Z 2201 as illustrated in Figure 2.

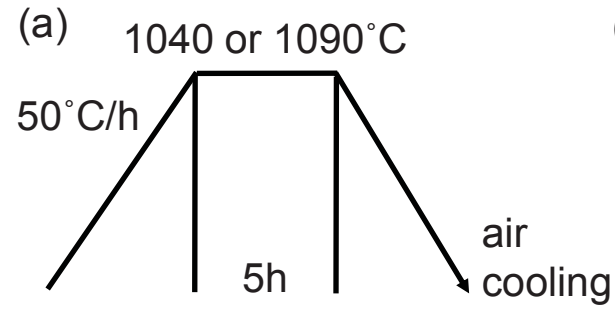

\section{$\underline{\text { Microstructure observations and mechanical tests }}$}

For microstructure observation, small cubic sample pieces of approximately $20 \mathrm{~mm}$ in length were cut from the heat treated plates. These samples were mechanically polished using abrasive papers up to $\# 1000$ and a polishing paste with diamond particles of $3 \mu \mathrm{m}$ in size, followed by electrolytic etching. The grain size numbers of the alloys were measured using optical microscopy in accordance with JIS G 0551. The detailed microstructure was examined by a field-emission scanning electron microscope (FESEM) and a transmission electron microscope (TEM) equipped with an energy dispersive spectrometer (EDS).

The grain boundary coverage $\rho$ was quantitatively evaluated in this work using the following definition; $\rho=L / L_{0}$, where $L$ and $L_{0}$ were the length of grain boundary covered with precipitates and the total length of grain boundary, respectively. The total length of the grain boundaries analyzed for each alloy is about $330 \mu \mathrm{m}$, using image analysis of at least five low magnification FE-SEM micrographs by an image processing software WinROOF version 3.40. The total number of observed grains for calculating $\rho$ were approximately 20 for each sample, however, the variation in $\rho$ with respect to grain orientation was unknown. Tensile tests were carried out at room temperature and at $700{ }^{\circ} \mathrm{C}$ in accordance with JIS Z 2241 and JIS G 0567, respectively. The strain was measured by the strain gauge attached to the annular protrusions of the gauge portion of the specimens. Creep tests were performed at $700{ }^{\circ} \mathrm{C}, 333 \mathrm{MPa}$ in accordance with JIS Z 2271. The strain during creep deformation was measured using the extensometer attached in the same way like the strain gauge in case of the tensile tests.

Figure 1. A series of heat treatments employed to the alloys studied: (a) solution heat treatment and (b) aging.

(a)

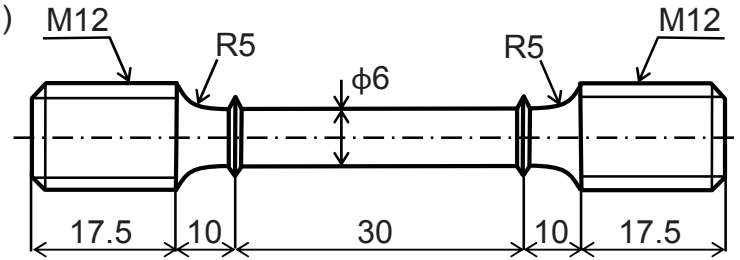

(b)

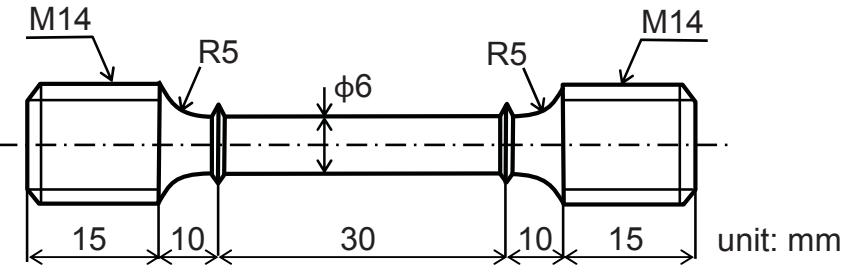

(b)

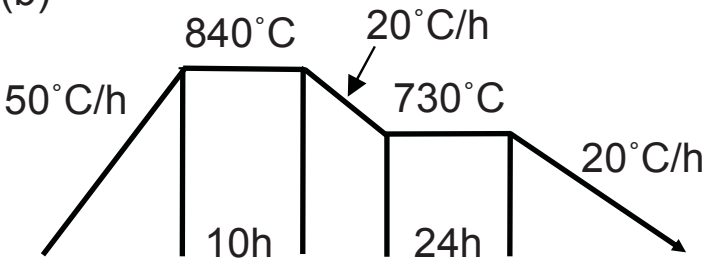

igure 2. Dimensions of specimen for (a) tensile test and (b) creep test. 
Table II . Strength and grain size of the alloys studied.

\begin{tabular}{|c|c|c|c|c|c|c|c|}
\hline \multirow{2}{*}{ Alloy } & \multirow{2}{*}{$\begin{array}{l}\text { Phosphorus } \\
\text { content, } C_{\mathrm{p}} \\
\text { (mass ppm) }\end{array}$} & \multicolumn{2}{|c|}{$\begin{array}{c}0.2 \% \text { proof stress, } \\
\sigma_{0.2} / \mathrm{MPa}\end{array}$} & \multicolumn{2}{|c|}{$\begin{array}{c}\text { Tensile strength, } \\
\sigma_{\mathrm{u}} / \mathrm{MPa}\end{array}$} & \multirow{2}{*}{$\begin{array}{l}\text { Grain size } \\
\text { number, } G\end{array}$} & \multirow{2}{*}{$\begin{array}{l}\text { Mean grain } \\
\text { size, } d / \mu \mathrm{m}\end{array}$} \\
\hline & & $\begin{array}{l}\text { room } \\
\text { temp. }\end{array}$ & $700^{\circ} \mathrm{C}$ & $\begin{array}{l}\text { room } \\
\text { temp. }\end{array}$ & $700^{\circ} \mathrm{C}$ & & \\
\hline $\mathrm{S} 1$ & 8 & 756 & 581 & 1174 & 742 & 3.4 & 109 \\
\hline S2 & 45 & 750 & 607 & 1177 & 765 & 3.4 & 109 \\
\hline S3 & 130 & 743 & 606 & 1175 & 769 & 3.1 & 121 \\
\hline S4 & 200 & 767 & 589 & 1186 & 753 & 3.3 & 113 \\
\hline S5 & 450 & 734 & 585 & 1161 & 760 & 3.1 & 121 \\
\hline
\end{tabular}
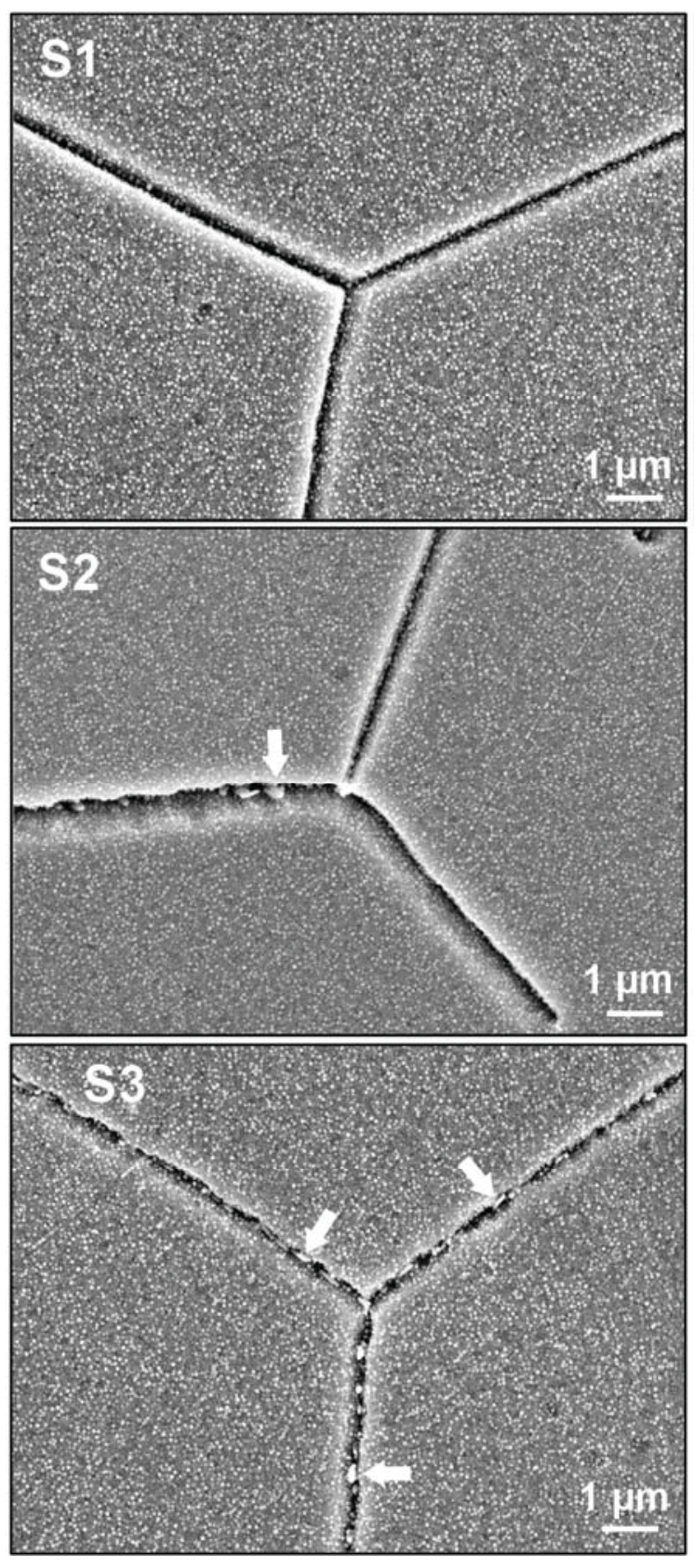
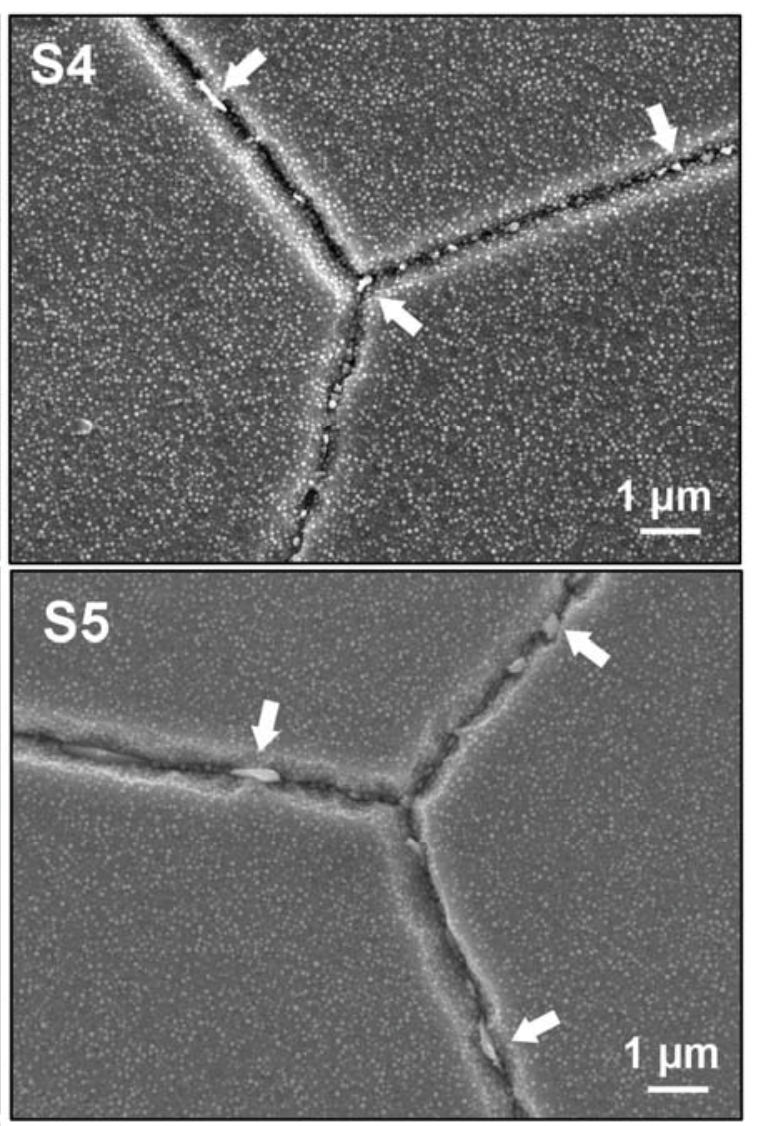

Figure 3. FE-SEM micrographs in the vicinity of grain boundaries of the alloys studied after the series of heat treatment. White arrow indicates a distinct precipitate at the grain boundaries. 


\section{Results}

\section{Microstructure observations and tensile tests}

Table II summarizes the results of tensile tests at room temperature and at $700{ }^{\circ} \mathrm{C}$, together with the grain size number and mean grain size of the alloys studied. The values of $0.2 \%$ proof stress, $\sigma_{0.2}$ are within a range of 734 to $764 \mathrm{MPa}$ at room temperature and 581 to $607 \mathrm{MPa}$ at $700{ }^{\circ} \mathrm{C}$. The values of tensile strength, $\sigma_{\mathrm{u}}$ are in a range of 1161 to $1186 \mathrm{MPa}$ at room temperature and 742 to $769 \mathrm{MPa}$ at $700{ }^{\circ} \mathrm{C}$. Thus, for both values of $\sigma_{0.2}$ and $\sigma_{\mathrm{u}}$, no remarkable differences were observed among the alloys, regardless of phosphorus contents. Note that the grain size numbers of the alloys were nearly the same among the alloys.

Figure 3 shows the FE-SEM micrographs in the vicinity of the grain boundaries of the alloys after aging. In $\mathrm{S} 1$, no precipitate is observed whereas the other alloys have the aggregated precipitates at the grain boundaries, as pointed by the arrows in the micrographs. Very fine particles with approximately $50 \mathrm{~nm}$ in size observed in the grain interior of all alloys were gamma prime phase, and the morphology is independent of the phosphorus content. The other phases such as gamma double prime phase were not observed. No precipitation free zone (PFZ) was observed along grain boundary in any of the alloys. Figure 4 shows the TEM micrograph and the result of elemental TEM-EDS mapping analysis of the grain boundary precipitates observed in S3 after aging. The precipitates are larger than the particles of gamma prime phase and mainly consist of phosphorus and niobium. Since no carbon and carbide former elements such as titanium and chromium were enriched, the precipitates should be a phosphide, rather than carbides.

Table III and Figure 5 show the relationship between the grain boundary coverage, $\rho$ and the phosphorus content in the alloys after the heat treatment. The $\rho$ increases with increasing phosphorus content, and shows the maximum value of 0.56 at the phosphorus content of $130 \mathrm{ppm}$, followed by sharp drop with phosphorus content to $200 \mathrm{ppm}$. In case of the phosphorus contents of 200 and $450 \mathrm{ppm}$, the $\rho$ almost remains unchanged of about 0.3 .

Table III. Grain boundary coverage of the alloys studied.

\begin{tabular}{c|c|c}
\hline Alloy & $\begin{array}{c}\text { Phosphorus } \\
\text { content, } C_{\mathrm{p}} \\
\text { (mass ppm) }\end{array}$ & $\begin{array}{c}\text { Grain } \\
\text { boundary } \\
\text { coverage, } \rho\end{array}$ \\
\hline S1 & 8 & 0 \\
S2 & 45 & 0.18 \\
S3 & 130 & 0.56 \\
S4 & 200 & 0.30 \\
S5 & 450 & 0.29 \\
\hline
\end{tabular}
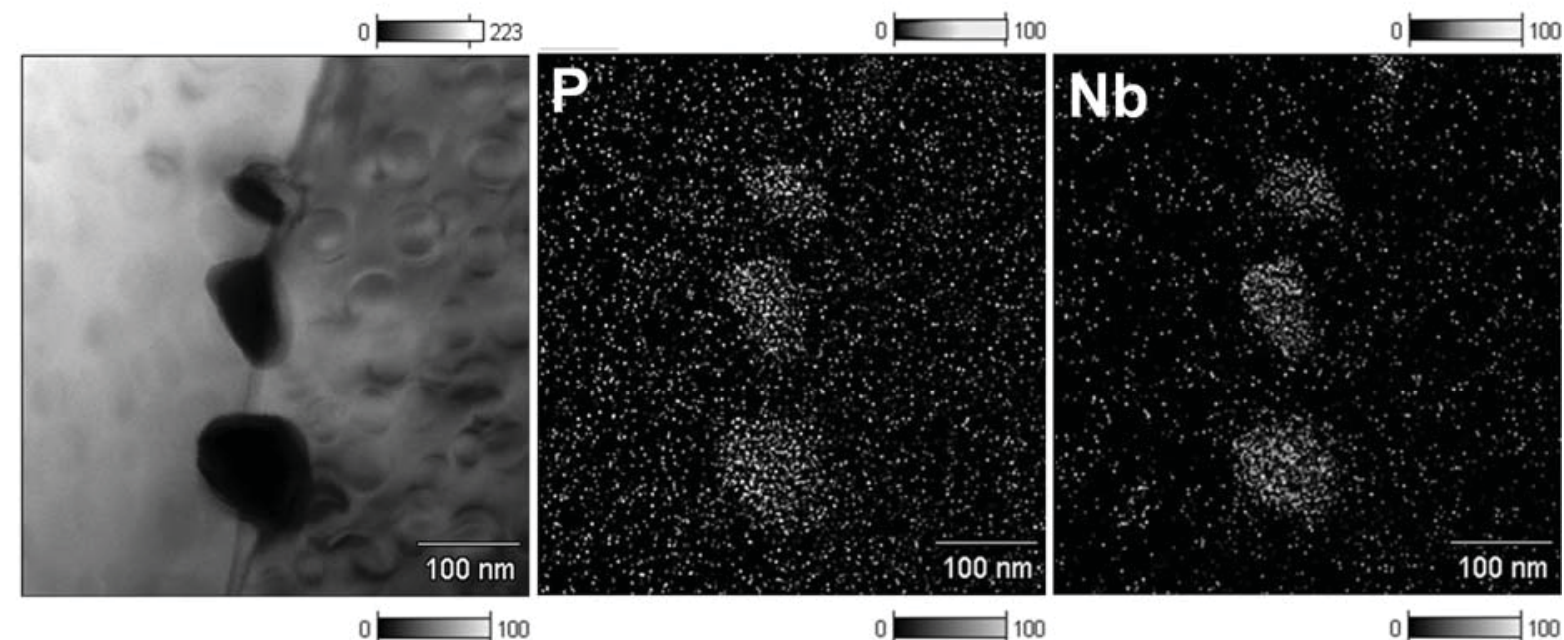

0

100
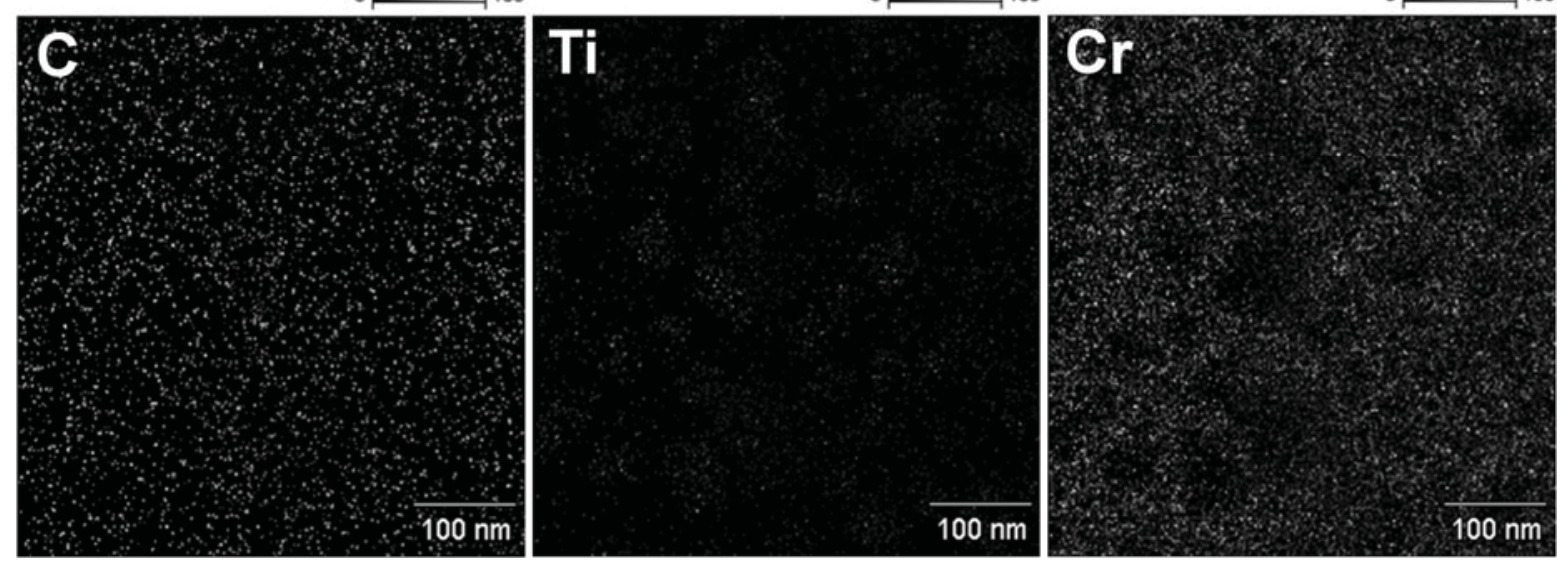

Figure 4. TEM micrograph and the result of elemental TEM-EDS mapping analysis of the grain boundary precipitates observed in $\mathrm{S} 3$ after the series of heat treatment. 


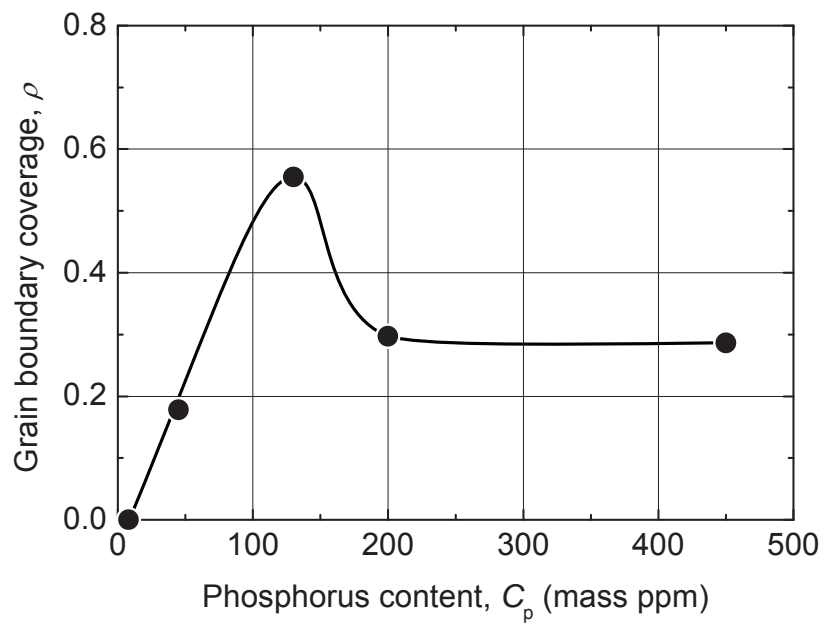

Figure 5. Relationship between grain boundary coverage of precipitates and phosphorus content in the alloys after the series of heat treatment.

\section{$\underline{\text { Creep test }}$}

All of the results of the creep tests in the alloys studied are summarized in Table IV. Figure 6 shows the creep rate versus time curves of the alloys at $700{ }^{\circ} \mathrm{C}, 333 \mathrm{MPa}$. In comparison to $\mathrm{S} 1$, the minimum creep rates of the other phosphorus added alloys were significantly small. Especially, the minimum creep rate of S3 was the smallest, and two orders of magnitude smaller than that of S1.

In addition, the time until to reach the minimum creep rate becomes prominently longer by phosphorus additions. Change in creep rate with creep strain of the alloys studied is shown in Figure 7. The creep rates of all alloys rapidly decrease at the beginning of the creep tests, and once reached to the minimum creep rates, they are increased monotonically. These results imply that the creep deformation of the alloys tested in this work only consists of the transient and accelerating creep stages, without steady-state stage. The creep rate of S3 decreased sharply from the beginning of the creep test, and reached the smallest minimum creep rate among the alloys studied.

Figures 8 and 9 show the phosphorus content dependence of the time to rupture and minimum creep rate, respectively. The two diagrams revealed a similar tendency of the relationship between grain boundary coverage and phosphorus content shown in Figure 5 , that is, the minimum creep rate and the time to rupture show a peak at the phosphorus content of $130 \mathrm{ppm}$.

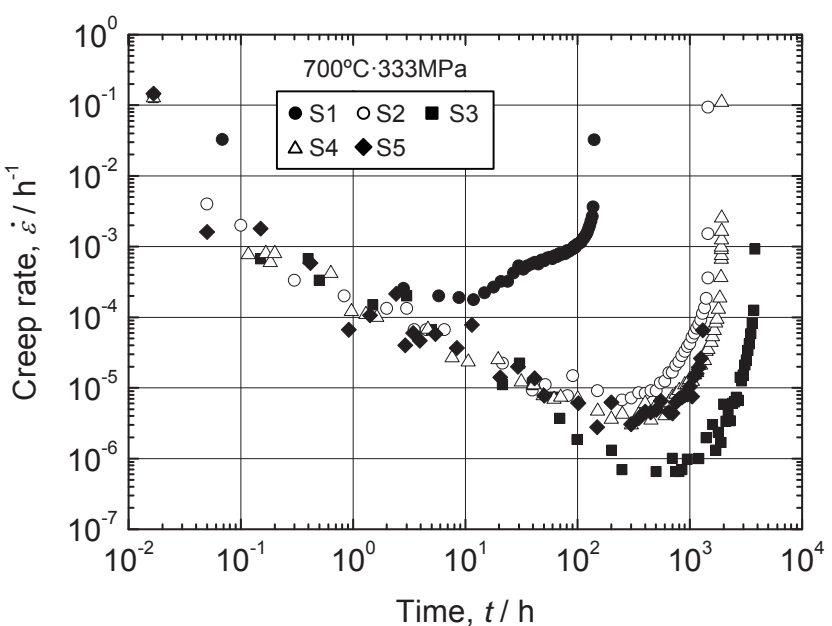

Figure 6. Creep rate versus time curves of the alloys at $700{ }^{\circ} \mathrm{C}, 333 \mathrm{MPa}$.

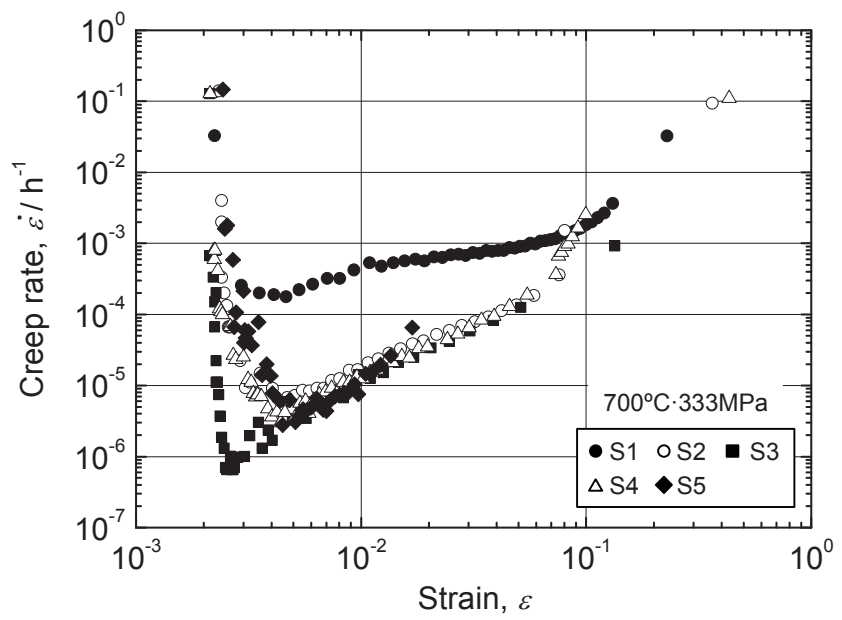

Figure 7. Creep rate versus strain curves of the alloys at $700{ }^{\circ} \mathrm{C}, 333 \mathrm{MPa}$.

Table IV. Results of creep tests of the alloys studied.

\begin{tabular}{c|c|c|c|c|c|c|c}
\hline Alloy & $\begin{array}{c}\text { Phosphorus } \\
\text { content, } C_{\mathrm{p}} \\
\text { (mass ppm) }\end{array}$ & $\begin{array}{c}\text { Temperature, } \\
T /{ }^{\circ} \mathrm{C}\end{array}$ & $\begin{array}{c}\text { Stress, } \\
\sigma / \mathrm{MPa}\end{array}$ & $\begin{array}{c}\text { Time to } \\
\text { rupture, } \\
t_{\mathrm{r}} / \mathrm{h}\end{array}$ & $\begin{array}{c}\text { Minimum creep rate, } \\
\dot{\varepsilon}_{\text {mim }} / \mathrm{h}^{-1}\end{array}$ & $\begin{array}{c}\text { Elongation, } \\
\text { El (\%) }\end{array}$ & $\begin{array}{c}\text { Reduction of } \\
\text { area, } R A(\%)\end{array}$ \\
\hline S1 & 8 & & & 139.6 & $1.4 \times 10^{-4}$ & 15.6 & 24.9 \\
S2 & 45 & \multirow{2}{*}{700} & 333 & 3789.1 & $7.7 \times 10^{-7}$ & 9.6 & 21.1 \\
S3 & 130 & & & 1923.5 & $4.1 \times 10^{-6}$ & 12.4 & 34.1 \\
S4 & 200 & & & 1303.8 & $4.0 \times 10^{-6}$ & 3.1 & 8.5 \\
S5 & 450 & & & & 1452.4 & $6.5 \times 10^{-6}$ & 3.4 \\
\hline
\end{tabular}




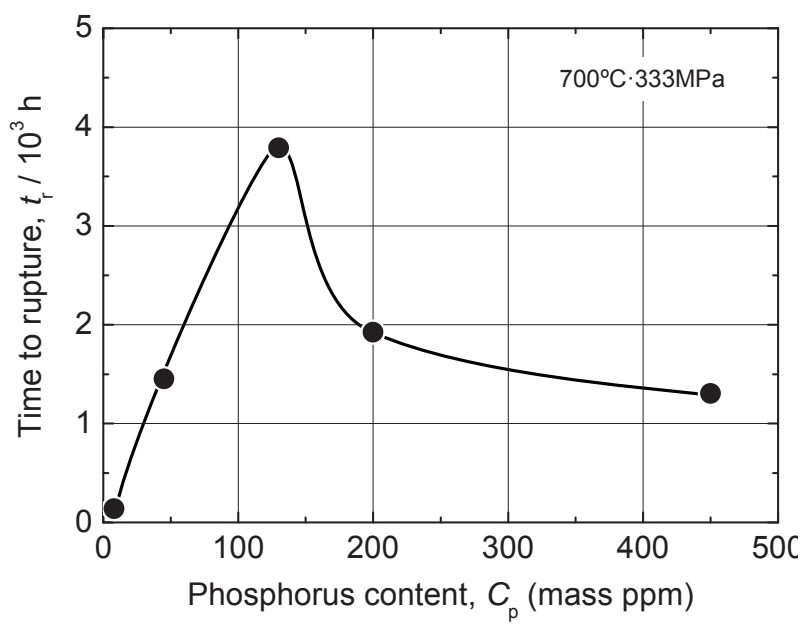

Figure 8 . Time to rupture at $700{ }^{\circ} \mathrm{C}, 333 \mathrm{MPa}$ of the alloys plotted as a function of phosphorus content.

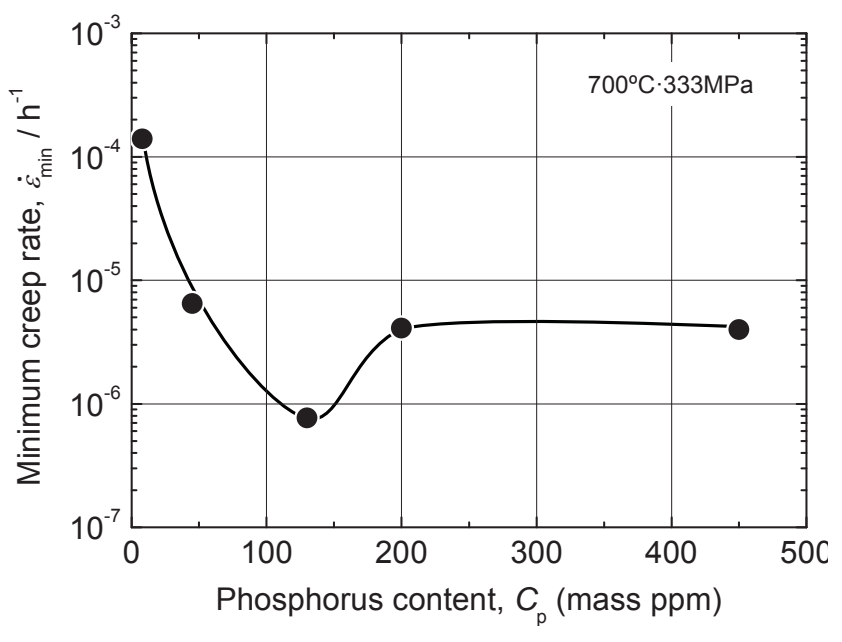

Figure 9. Minimum creep rate at $700{ }^{\circ} \mathrm{C}, 333 \mathrm{MPa}$ of the alloys plotted as a function of phosphorus content.

Figure 10 is a typical FE-SEM micrograph in the vicinity of a grain boundary of $\mathrm{S} 3$ after creep rupture. It was confirmed that the precipitates remained at the grain boundary as indicated by the white arrows, and no PFZ appeared during creep test. However, some cavity-like regions could be seen between precipitates as indicated by the black arrows. These regions extended toward the inside of the grains with a length of approximately $1 \mu \mathrm{m}$ or less.

\section{Discussion}

Optimum phosphorus content and effect of grain boundary coverage on time to rupture and minimum creep rate

As shown in Figures 3 and 4, phosphorus preferentially forms precipitates mainly consisting of phosphorus and niobium at the grain boundary. The grain boundary precipitates do not strongly affect the short-term tensile properties, but the creep deformation. Although even as several tens of phosphorus addition increase the time to rupture and decrease the minimum creep rate, Figures 8 and 9 clearly demonstrate that the optimum phosphorus content in the nickel-iron base superalloy used in this study is $130 \mathrm{ppm}$.

The results obtained in this work basically agree with those reported by Guo et al. [12]; the $0.2 \%$ proof stress and tensile stress of Inconel $718^{\mathrm{TM}}$ at room temperature and at $650{ }^{\circ} \mathrm{C}$ did not change, and the time to rupture at $650{ }^{\circ} \mathrm{C}, 650 \mathrm{MPa}$ peaked at the phosphorus content of $0.013 \%$. Heaney et al. [11] also mentioned that controlled phosphorus addition between 80 and $150 \mathrm{ppm}$ would be effective for the improvement in creep performance of Inconel $718^{\mathrm{TM}}$. Although there are some differences in the chemical composition between Inconel $718^{\mathrm{TM}}$ and the alloy used in this study, the suitable phosphorus content to improve creep properties is seemed to be equal.

However, the previous works quoted above did not explain adequately the reason why the creep rupture life was particularly extended at a specific phosphorus content. In this study, a good correspondence in the dependence of correlations between the grain boundary coverage and time to rupture and minimum creep rate as a function of the phosphorus content are recognized as shown in Figures 5, 8 and 9. Based on these results, the maximization of the time to rupture and the minimization of the minimum creep rate are obviously attributable to the maximization of the grain boundary coverage.

The microstructure shown in Figure 10 contains important information. The cavity-like regions exist between the grainboundary precipitates and extend toward grain interior. The dark contrast of the cavity-like region indicates that there is a slight misorientation with respect to the surrounding matrix region. These facts and the obvious relationship between creep properties (minimum creep rate and time to rupture) and grain boundary coverage strongly indicate that the local deformation preferentially occurs in the uncovered regions under creep. In other words, the grain-boundary precipitates suppress the local deformation, and the higher the $\rho$, the less the local deformation occurs.

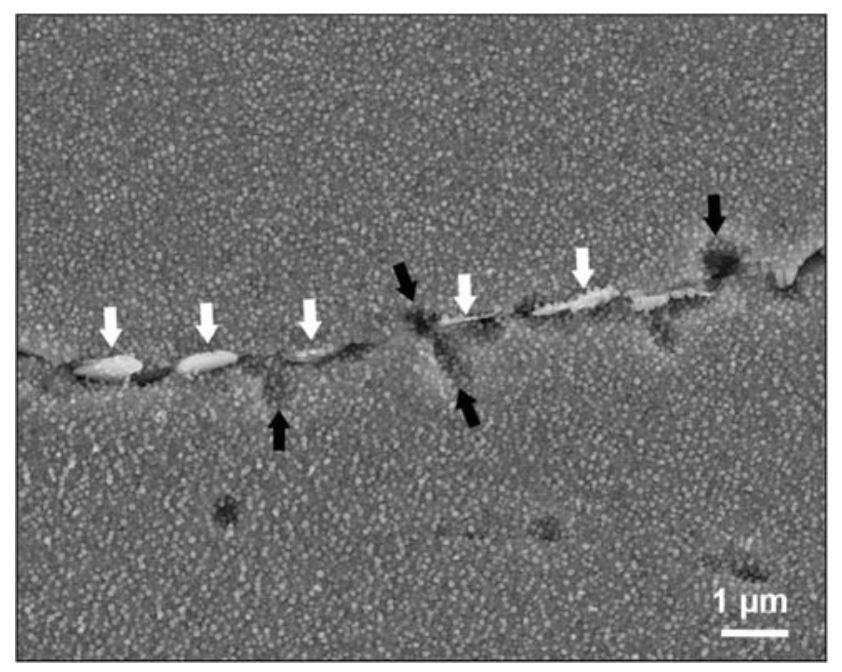

Figure 10. FE-SEM image in the vicinity of a grain boundary of the alloy S3 after creep test. The white and black arrow shows a distinct grain-boundary precipitate and the cavity-like region, respectively. 


\section{Effects of phosphorus on the creep deformation behavior}

The creep deformation of the alloys proceeds through the transient and accelerating creep stages as mentioned in the chapter of experimental results. The relationship between the onset time of the accelerating creep stage normalized by the time to rupture, $t_{\mathrm{an}}$, and grain boundary coverage is plotted as shown in Figure 11. The vertical axis represents the fraction of the time consumed

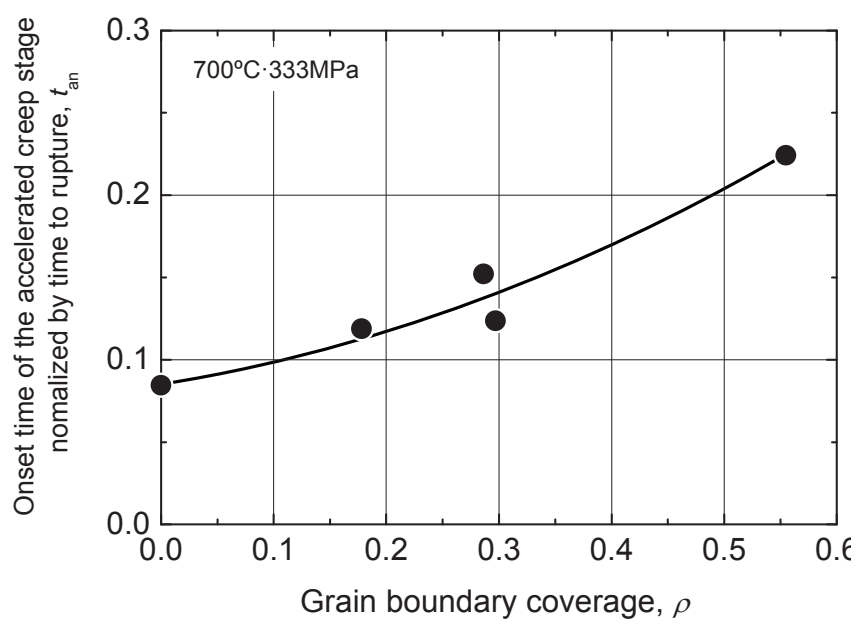

Figure 11. Relationship between the onset time of the accelerating creep stage normalized by time to rupture and grain boundary coverage of the alloys at $700{ }^{\circ} \mathrm{C}, 333 \mathrm{MPa}$.

during the transient creep stage to the entire rupture life. When the grain boundary coverage is zero, that is, no phosphorus is added, the value of $t_{\mathrm{an}}$ is less than 0.1. The value of $t_{\mathrm{an}}$ increases monotonically with increasing grain boundary coverage. This means that if the grain boundary is not covered with precipitates, the creep deformation will soon enter into the accelerating stage. Based on this analysis, one of the effects of the grain-boundary precipitation strengthening confirmed in the present work can be interpreted as retardation of the onset of the accelerating creep stage. Figure 12 shows the relationship between creep strain at the beginning of the accelerating creep stage, $\varepsilon_{\mathrm{a}}$ and $\rho$. The $\varepsilon_{\mathrm{a}}$

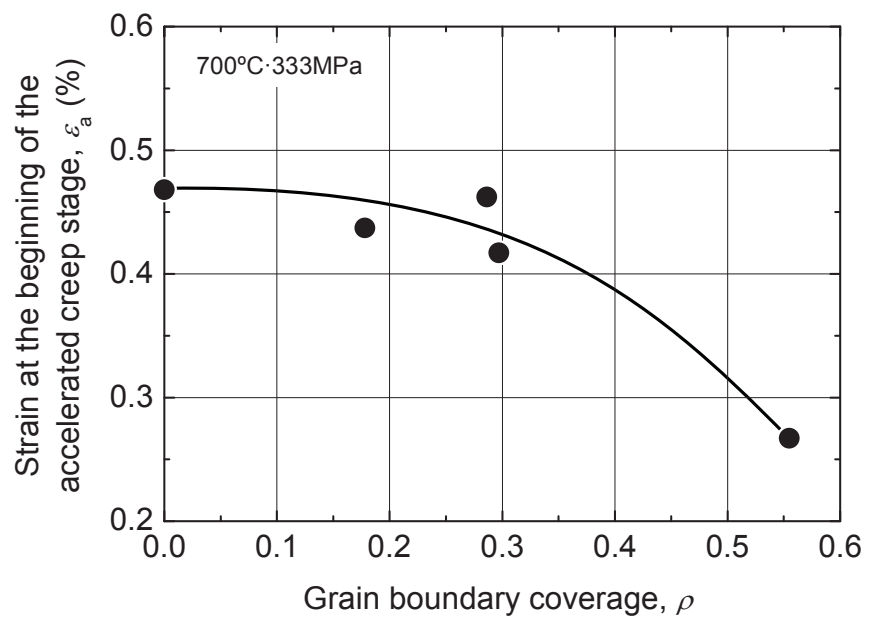

Figure 12. Relationship between strain at the beginning of the accelerating creep stage and grain boundary coverage of the alloys at $700^{\circ} \mathrm{C}, 333 \mathrm{MPa}$. decreases with increasing $\rho$, i.e. the strain generated during the transient creep stage becomes small with increasing grain boundary coverage. This tendency can be explained by the sharp drop of the creep rate just after the beginning of the creep test observed in the phosphorus-added alloys, as shown in Figure 7. Comparing with the total elongation listed in Table IV, most of the elongation is generated during the accelerating creep stage. Therefore, the grain-boundary precipitation strengthening is effective in suppress creep deformation, thereby delaying the beginning of the accelerating creep stage. The relationship between time to rupture, $t_{\mathrm{r}}$, and minimum creep rate $\dot{\varepsilon}_{\min }$ is known as Monkman-Grant relationship [20] as follows

$$
t_{\mathrm{r}} \cdot \dot{\varepsilon}_{\min }^{m}=C
$$

where $m$ and $C$ is a constant. If the exponent $m$ equal unity, the creep deformation is thought to be controlled predominantly by transgranular deformation [21]. Figure 13 shows time to rupture plotted as a function of minimum creep rate in accordance with eq. (1). The exponent $m$, which corresponds to the slope of the regression line drawn in Figure 13, is calculated to approximately 0.6. Although the five available data points are so insufficient as to accurately determine the fitting parameters of eq. (1), the obtained value of $m$ is considered to be at least lower than unity. This result implies that the creep deformation of the alloys was not strongly affected by the transgranular deformation but the deformation occurred in the vicinity of grain boundaries. The absence of obvious difference in $0.2 \%$ proof stress and size of gamma prime phase particles recognized among the alloys also supports the idea that the improvement of creep properties is not attributed to the transgranular deformation. Details still remain unknown. However, provided that the mechanism of grainboundary precipitation strengthening proposed by Takeyama [22] works in the alloys of this work, the grain boundary precipitates may reduce the preferential deformation confined to the vicinity of grain boundaries during creep deformation. Consequently, the suppression of the local deformation by grain-boundary precipitates is responsible for the retardation of the onset of accelerating creep, thereby leading to the extension of the rupture life.

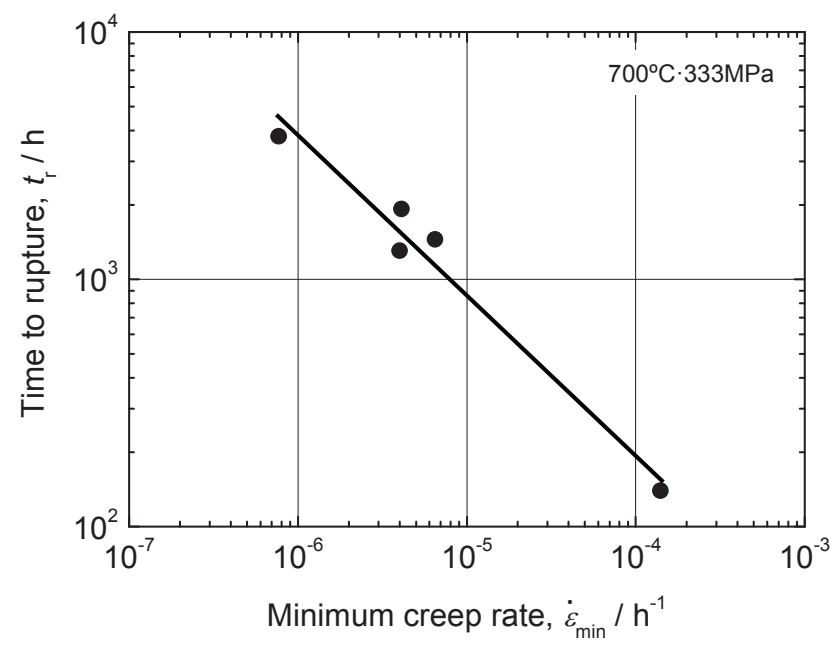

Figure 13. Relationship between the times to rupture and minimum creep rates of the alloys at $700{ }^{\circ} \mathrm{C}, 333 \mathrm{MPa}$ obtained in accordance with the Monkman-Grant relationship ${ }^{20)}$ (solid line). 


\section{Conclusions}

This work focused on the investigation of the effect of phosphorus on the creep properties of a nickel-iron base superalloy, especially from the standpoint of grain-boundary precipitation strengthening. The main findings are summarized as follows:

(1) The time to rupture increased by up to approximately 30 times and the minimum creep rate decreased by up to more than 2 orders of magnitude with increasing phosphorus content up to 130 ppm. Phosphorus formed niobium-phosphorus precipitates at grain boundaries.

(2) The grain boundary coverage of niobium-phosphorus precipitates showed a maximum value of approximately 0.56 in the alloy containing phosphorus of $130 \mathrm{ppm}$, and the time to rupture and minimum creep rate were also peaked. Thus, the grain boundary coverage is a decisive factor to improve the creep strength.

(3) The effect of the grain-boundary precipitation strengthening confirmed in the present work is to suppress the local deformation along the grain boundaries, which is responsible for the retardation of the beginning of the accelerating creep stage and suppression of its progress, leading to the extension of rupture life.

\section{References}

1. F. Masuyama, "R\&D Program for A-USC Material Development with Creep Strength/Degradation Assessment Studies," Proc. of 6th Int. Conf. on Advances in Material Technology for Fossil Power Plants, ASM International, Materials Park, OH, (2010), 11.

2. S. Ohsaki, T. Takahashi, S. Imano, J. Sato and E. Saito, "Effect of Grain Size on Mechanical Properties of Ni-Fe Base Superalloy for Advanced USC Turbine Rotor Materials," Proc. of 6th Int. Conf. on Advances in Material Technology for Fossil Power Plants, ASM International, Materials Park, OH, (2010), 361.

3. R. Yamamoto, Y. Kadoya, T. Nakano and S. Kurata, "Development of Ni-based Superalloy for Advanced $700^{\circ} \mathrm{C}$-class Steam Turbines," Proc. of 5th Int. Conf. on Advances in Material Technology for Fossil Power Plants, ASM International, Materials Park, OH, (2007), 3B-04.

4. A. Diwo, B. Donth, N. Blaes, D. Bokelmann, Y. Yoshioka, S. Miyashita and T. Kubo, "Largest Steam Turbine Rotor Ever Manufactured," Proc. of 18th International Forgemasters Meeting, Forging Industry Association, Cleveland, OH, (2011), 219-223.

5. Elihu F. Bradley, SUPERALLOYS A Technical Guide (ASM International, Materials Park, OH, 1988), 21.

6. S. Imano, J. Sato, K. Kajikawa and T. Takahashi, "Mechanical Properties and Manufacturability of Ni-Fe base Superalloy (FENIX-700) for A-USC Steam Turbine Rotor Large Forgings," Proc. of 5th Int. Conf. on Advances in Material Technology for Fossil Power Plants, ASM International, Materials Park, OH, (2007), 3B-03.

7. T. B. Gibbons, "Some Effects of Trace Elements in Reducing Creep Performance of High-Strength Superalloy," Mater. Sci. Technol., 1(1985), 1033-1039.
8. M. McLean and A. Strang, "Effects of Trace Elements on Mechanical Properties of Superalloy," Met. Technol., 11(1984), 454-475.

9. X. Liu, J. Dong, B. Tang, Y. Hu and X. Xie, "Investigation of the Abnormal Effects of Phosphorus on Mechanical Properties of INCONEL718 Superalloy," Mater. Sci. Eng. A., 270 (1999), 190196.

10. W. R. Sun, H. R. Guan, M. Wang, Z. G. Wang, L. F. Huang and Z. Q. Hu, "Influence of Phosphorus on Deformation Mechanism and Mechanical Properties of IN718 Alloy," Proc. of 6th Int. Symp. on Superalloys 718, 625, 706 and Derivatives, The Minerals, Metals and Materials Society, Warrendale, PA, (2005), 399-407.

11. J. Heaney, W. Buttrill, J. Russell and P. Mrowczynski, "Influence of Phosphorus on Creep Performance of DA Alloy 718," Proc. of 6th Int. Symp. on Superalloys 718, 625, 706 and Derivatives, The Minerals, Metals and Materials Society, Warrendale, PA, (2005), 687-698.

12. S. Guo, W. Sun, D. Lu and Z. Hu, "Effect of Minor Elements on Microstructure and Mechanical Properties," Proc. of Int. Symp. on Superalloys 718, 625, 706 and Various Derivatives, The Minerals, Metals and Materials Society, Warrendale, PA, (1997), 521-530.

13. W. D. Cao and R. L. Kennedy, "Effect and Mechanism of Phosphorus and Boron on Creep Deformation of Alloy718," Proc. of Int. Symp. on Superalloys 718, 625, 706 and Various Derivatives, The Minerals, Metals and Materials Society, Warrendale, PA, (1997), 511-520.

14. J. A. Horton, C. G. McKamey, M. K. Miller, W. D. Cao and R. L. Kennedy, "Microstructural Characterization of Superalloy 718 with Boron and Phosphorus Additions," Proc. of Int. Symp. on Superalloys 718, 625, 706 and Various Derivatives, The Minerals, Metals and Materials Society, Warrendale, PA, (1997), 401-408.

15. W. D. Cao and R. L. Kennedy, "Improving Stress Rupture Life of Alloy 718 by Optimizing Al, Ti, P and B Contents," Proc. of Int. Symp. on Superalloys 718, 625, 706 and Various Derivatives, The Minerals, Metals and Materials Society, Warrendale, PA, (2001), 477-488.

16. Elihu F. Bradley, SUPERALLOYS A Technical Guide (ASM International, Materials Park, OH, 1988), 18.

17. Chester T. Sims, Norman S. Stoloff and William C. Hagel, SUPERALLOYS II (A Wiley-Interscience Publication, New York, NY, 1987), 256.

18. M. Takeyama, "Recent Trend on Materials Development for A-USC Power Plants," DENKI-SEIKO, 83(2012), 27-33.

19. Y. Misosaku, I. Tarigan, N. Takata, M. Ueda, T. Maruyama and M. Takeyama: "Creep of the Novel Austenitic Heat Resistant Steel of Fe-20Cr-30Ni-2Nb under Steam Atmosphere at 1073K" Proc. of 7th Int. Conf. on Advances in Material Technology for Fossil Power Plants, ASM International, Materials Park, OH, (2013), 1352. 
20. F. C. Monkman and N. J. Grant, "An empirical relationship between rupture life and minimum creep rate in creep-rupture tests," Proc. ASTM, 56(1956), 593-620.

21. K. Maruyama and H. Nakashima, Kohonkyodo no Zairyokagaku, (Uchida Rokakuho, Tokyo, 1997), 154.

22. M. Takeyama, "Fundamental of Physical Metallurgy for HighTemperature Materials -Microstructure Control and Design-," 194th Nishiyama Memorial Lecture, The Iron and Steel Institute of Japan, Tokyo, (2008), 1-23. 